\title{
Revista \\ Brasileira \\ de Enfermagem \\ REBEn Referências para o ensino de competências na enfermagem
}

PESQUISA

\author{
References for competence teaching in nursing \\ Referencias para la formación por competencia en enfermería
}

Edvane Birelo Lopes De Domenico

Prefessora Doutora da Universidade Paulista (UNIP). Coordenadora dos Cursos de Graduação e Especialização em Enfermagem. Endreço: Rua Dr. Bacelar, 1212. CEP 04026-002 - São Paulo - SP. erdomenico@sti.com.br

Cilene Aparecida Costardi Ide

Professora Titular na Escola de Enfermagem da Universidade de São Paulo, Departamento de Enfermagem Médico-Cirúrgica - ENC.

Esta revisão de literatura é parte integrante da tese de doutorado: De Domenico EBL. Referências de competências segundo níveis de formação superior em enfermagem: a expressão do conjunto [tese]. São Paulo (SP): Escola de Enfermagem da USP; 2003.

\section{RESUMO}

O presente artigo de revisão de literatura traz referências pedagógicas para a implantação de um projeto de ensino por competências para a formação de enfermeiros, destacando as bases de sustentação deste projeto e o modelo formativo de avaliação.

Descritores: Educação em enfermagem; Educação baseada em competências; Competência profissional.

\section{ABSTRACT}

The present literature review introduces pedagogical references for the implantation of a teaching by competences project to the nursing education, emphasizing the support of this project and the formative model of evaluation. Descriptors: Education, nursing, Competency-based education, Professional competence.

\section{RESUMEN}

El artículo presenta referencias pedagógicas para la implantation de um proyecto de enseñanza por competência para la formación de enfermeras, destacando las bases de sustentar este proyecto y el modelo de formación cualitativa.

Descriptores: Educación en enfermería; Educación basada en competencia; Competencia profesional.

De Domenico EBL, Ide CAC. Referências para o ensino de competências na enfermagem. Rev Bras Enferm 2005 jul-ago; 58(4):453-7.

\section{INTRODUÇÃO}

O processo de ensino baseado na construção de competências, primordialmente significa reconhecer que as relações do mundo estão mudadas, e que, sendo assim, a formação educacional do profissional também precisa ser outra.

O presente artigo não tem a pretensão de trazer um modelo, mas sim os pontos analíticos dessa nova abordagem do ensino para que possam gerar inquietações e discussões por parte tanto de docentes como de alunos. Considerando a literatura publicada sobre a temática tanto na área da Educação como na própria Enfermagem, foram destacados pontos que se delineiam como pilares de sustentação de uma nova proposição.

\section{CAMINHOS E PRESSUPOSTOS PEDAGÓGICOS}

Não obstante as transformações do mundo do trabalho encontram-se as transformações exigidas para a formação educacional. A reestruturação da educação é urgente, na medida que a transmissão de conhecimentos não garante a formação de indivíduos capazes de modificarem uma prática, de apresentarem novos resultados. É preciso que eles sejam competentes.

Apesar dessas construções, no universo da educação formal o sistema cartesiano ainda é dominante, prevalecendo o encadeamento linear, os pré-requisitos, a seriação. As disciplinas, neste modelo, desempenham individualmente um papel predominante e mantém relações hierárquicas entre si, na forma de pré-requisitos ${ }^{(1,2)}$.

Os referenciais pedagógicos expostos a seguir estruturam ideologicamente e metodologicamente a proposição de um ensino por competências:

- "É preciso substituir o pensamento que isola e separa por um pensamento que distingue e une". A interligação de todos os conhecimentos combate o reducionismo, uma vez que a simplicidade não exprime a unidade e a diversidade presentes no todo ${ }^{(3)}$;

- "Competência em educação é mobilizar um conjunto de saberes para solucionar com eficácia 
uma série de situações"(4);

- "Um plano curricular precisa satisfazer de forma articulada, todos os níveis de funcionamento de uma escola". Numa concepção construtivista do processo ensino-aprendizagem a prioridade é que 0 aluno aprenda e não que o professor ensine ${ }^{(5)}$;

- "Só o profissional pode ser o responsável por sua formação", porém o trabalho de educação continuada é coletivo e dependente da experiência e da reflexão como instrumentos contínuos de análise ${ }^{(6)}$;

- "A educação tem que servir a um projeto da sociedade como um todo". Mobilizar é convocar vontades para atuar na busca de um propósito comum, sob uma interpretação e um sentido também compartilhados ${ }^{(6)}$;

- "O melhor jeito de organizar o currículo é por projetos didáticos". Nessa proposta o docente abandona o papel de "transmissor de conhecimento" para se transformar num pesquisador, trabalhando com situações da vida real, estabelecendo objetivos, buscando evidências, tomando decisões ${ }^{(6)}$;

- "A idéia de rede constitui uma imagem emergente para a representação do conhecimento, inspirada, em grande parte, nas tecnologias informacionais. Nesta perspectiva, conhecer é como enredar, tecer significações, partilfar significados. Os significados, por sua vez são construídos por meio de realções estabelecidas entre os objetos, as noções, os conceitos. Um significado é como um feixe de relações ${ }^{(7)}$.

A competência integra vários saberes, habilidades, "atitudes e posturas mentais, curiosidade, paixão, busca de significado, desejo de tecer laços, relação com o tempo, maneira de unir intuição e razão, cautela e audácia, que nascem tanto da formação como da experiência"(8).

Na pretensão é de se "ensinar tudo", como destaca Machado(7), pouco se reconhece ou considera os projetos dos alunos que freqüentam as instituições formadoras. E todo ser humano é movido por projetos, desejos de ação que o caracterizem num contexto social ampliado, para além da sua inserção familiar. Neste sentido, ser competente também deverá passar a ser um projeto para o aluno, principalmente na etapa de preparo profissional.

\section{A ABORDAGEM CURRICULAR POR COMPETÊNCIAS}

As incertezas são muitas, principalmente relacionadas aos métodos a serem utilizados por uma abordagem curricular por competências, bem como da sua capacidade de funcionar eficazmente. Certamente, mudanças na disposição e hierarquia dos saberes, bem como a compreensão e instrumentalização docente para atuar com este referencial são fundamentais.

Somando-se, estão questões que merecem análises reflexivas:

- Como implementá-la com alunos, continuamente apressados, perturbados, carregados em uma temporalidade fragmentada, sem tempo para experimentar (e experimentar-se), para pôr à prova (e pôrse à prova), para verificar, para hesitar, para tatear ${ }^{(4)}$ ?

- Como implementá-la quando os próprios professores não se permitem penetrar no território de uma outra disciplina e quando a cultura dominante da instituição, quase não autoriza a prática da transferência ${ }^{(4)}$ ?

- A transferência é cobrada do aluno como se para ele fosse algo inato, mas como equacionar isto se os próprios professores são representantes de um corpo de saberes disciplinares ${ }^{(4)}$ ?

O desafio lançado por essas referências compreende o dever de se deslocar o ensino da linha de montagem para uma rede de relações que faça da construção de competências a verdadeira arma para enfrentar os problemas e superá-los. O saber articulado não pode ser relacionado a um modismo porque a revolução da tecnologia certamente tem excluído, mais do que incluído os trabalhadores. Considerando os fatos e também querendo reconstruir uma expressão profissional demasiadamente dependente de normatizações e do controle de corpos e mentes, essas bases analíticas assumem destaque num ensino renovado da Enfermagem ${ }^{(9)}$.

\section{O ENSINO NA ENFERMAGEM}

Relacionando e buscando sentidos para o ensino, a literatura da Enfermagem já traz bases para edificações possíveis:

- Partir do nível de desenvolvimento de cada aluno(10).

- Ampliar o horizonte analítico, tendo a contingência do campo como realidade.

- Promover uma inserção gradativa e personalizada do estudante no processo de cuidar, a partir das experiências já assimiladas ${ }^{(10)}$.

- Valorizar as opções preferenciais dos estudantes na escolha das situações de aprendizagem ${ }^{(10)}$.

- Analisar conjuntamente o componente reiterativo- já assimiladoe 0 inédito- espaço de criação- enquanto elementos dos projetos de cuidar ${ }^{(10)}$.

- Distanciar-se gradativamente, ampliando o espaço e o exercício da autonomia discente ${ }^{(10)}$.

- Problematizar projetos no sentido de apreender sua sustentação teórica.

- Planejar conjuntamente as atividades, o espaço de inovação, para que cada docente, respeitando os princípios e objetivos gerais da disciplina possa desenvolver a prática de ensinar e do aprender a cuidar a partir das necessidades, expectativas e possibilidades mobilizadas pelo grupo discente e viabilizadas pela interação com a dinâmica da prática ${ }^{(6)}$.

- Avaliar processual e conjuntamente as dinâmicas de trabalho no sentido de promover os investimentos necessários à validação desse contrato simbólico em parceria com enfermeiros assistenciais, na condição também de referência para a formação ${ }^{(10)}$.

Nas relações de ensino-aprendizagem nas quais 0 esquadrinhamento, a dominação e a sujeição ocorrem com menor intensidade, "os corpos dos enfermeiros parecem também menos conformados e dóceis às forças de poder que buscam sujeita-los", conseguindo perceber e utilizar seus próprios corpos enquanto forças geradoras de mudanças ${ }^{(11)}$.

No âmbito do ensino da prática, Lunardi(12) pontuou que os instrumentos de avaliação das atividades de estágio de graduandos vêm impregnados pela subjetividade dos docentes, servindo como mais um instrumento de controle e dominação, na medida que podem punir pelo controle do tempo (atrasos e lentidão na execução de procedimentos); pela execução de procedimentos que fujam da técnica ensinada; pelos discursos; pelo modo de ser; pela advertência na desobediência; pelo uniforme.

No campo da Graduação, o estágio pré-profissional, como estratégia de ensino viável e fecunda, deveria "desenvolver relações de aproximação, de articulação e de unidade entre diferentes sujeitos, diferentes conhecimentos e diferentes realidades, permeadas pela interlocução dialógica, assumindo uma postura crítica face ao contexto histórico, fazendo opções políticas conscientes e agindo concretamente para aproximar a realidade da utopia desejada" ${ }^{(11)}$.

Investir no desenvolvimento de habilidades aptas a tornarem o enfermeiro capaz de Coordenar o Processo de Cuidar ${ }^{(13)}$, é uma proposta que conceitua o processo de cuidar enquanto "seqüência dinâmica e sistematizada de ações necessárias e suficientes para a construção, desempenho e validação do trabalho da equipe de enfermagem, agregando intervenções específica (cuidar dual), ações complementares e interdependentes do conjunto multiprofissional (assistir-cuidar) desenvolvidas em contextos institucionais peculiares"(13). 
Considerando a produção científica acelerada e a busca por resultados que agreguem eficiência e efetividade, a atitude investigativa é fundamental para o exercício de uma prática científica e sistematizada, que consiste no exercício da avaliação clínica e no processo de integração e aplicação das evidências externas àquela realidade observada. Estrategicamente, uma prática baseada em evidências baseia-se em cinco etapas. Primeiramente a necessidade de cuidado observada no paciente, num grupo de pacientes ou mesmo na organização do serviço, deve ser convertida numa pergunta; a segunda etapa consiste na busca bibliográfica da melhor evidência relacionada à pergunta. A seguir, as evidências encontradas são avaliadas em termos de validade e confiabilidade metodológica, além da sua aplicabilidade clínica. Na quarta etapa os achados escolhidos mediante a análise crítica são aplicados à prática clínica e, finalmente, a quinta etapa consiste na avaliação dos resultados ${ }^{(14-16)}$.

Temos que ter clareza do que é fundamental na formação dos profissionais de Enfermagem, nesse contexto de constantes mudanças, que não tenham como meta apenas privilegiar o mercado de trabalho, mas que visem basicamente a construção de uma nova sociedade, a formação de sujeitos críticos, capazes de sempre buscar o novo, de ousar ${ }^{(17)}$.

Desenvolver o pensamento crítico na Enfermagem é de longa data sugerido e recomendado. Este fazer "envolve um esforço bastante grande implicando em muito mais horas de trabalho e sobretudo, em um auto-exame sobre o significado do papel do educador na formação de futuros profissionais de Enfermagem" (18).

Dentre as estratégias existentes para o desenvolvimento do pensamento crítico, encontram-se: a) atividades de observação (nas quais as habilidades de ouvir, ver e sentir são as mais importantes); b) atividades de escrita (diários, questionários, trabalhos de reação, atividades de pesquisa, análise e síntese); c) atividades de ação (incluem simulações, jogos, situação-problema, entre outras); d) atividades combinadas: incidente crítico (técnica na qual evoca-se um incidente significativo e, a partir de instruções precisas para o que se deseja obter, podem ser trabalhados conceitos, opiniões, capacidade de observação, identificação de atitudes e comportamentos, entre outras possibilidades ${ }^{(18)}$.

"Se os alunos devem aprender a pensar e agir em situações complexas devem ter a oportunidade de desenvolver habilidades que exijam mais do que registrar os resultados dos seus estudos. (...) facilitar a expressão do raciocínio, da compreensão, da tomada de decisão e aprimoramento da capacidade de comunicação escrita são fundamentais"(19).

No campo da especialização, a demanda seria por um profissional que "medeia as relações entre a produção do conhecimento na Enfermagem e sua imediata utilização, vinculada não apenas à melhoria da qualidade da assistência, mas principalmente à qualidade de vida do seu cliente", sendo este um desafio atual para a Enfermagem ${ }^{(20)}$. No campo da pós-graduação Stricto-sensu os esforços deveriam concentrarse no domínio das teorias e metodologias de ensino como requisito para uma docência cientificamente sustentada e na validação de experimentos clínicos como instrumento de superação da abordagem majoritariamente exploratória-descritiva ainda prevalente nas pesquisas.

Todos os aspectos abordados até então são condições a serem respeitadas se a intenção da formação for a construção de competências. Escolher estratégias didáticas aptas a exercitarem esses pressupostos é fundamental e dependerá da intencionalidade do ensino, do preparo e envolvimento de docentes e da organização educacional, como também do envolvimento dos alunos, numa participação consciente e responsável pelo sucesso da proposta.

Com relação aos conteúdos programáticos têm-se nas palavras de
Cocco; Bagnato(17) que a seleção de conteúdos é essencial, pois não é possível discutir com o aluno todo o conhecimento disponível, além do fato que o mesmo pode ser rapidamente substituído, pela velocidade na geração de novas informações. Entretanto, é imprescindível possibilitar ao aluno 0 acesso às ferramentas de informação". Os autores advertem sobre a abrangência exagerada de conteúdos, uma vez que, "o educador que não tem o domínio do conhecimento que considera essencial, produzido na sua área, provavelmente terá dificuldade de ministrar um curso de excelência, sendo a carga horária sempre insuficiente para dar conta de um conteúdo amplo".

Nesse tipo de ação pedagógica centrada nos dados, nas informações, o "contrato do aluno é escutar, tentar entender, fazer os exercícios com aplicação e restituir suas aquisições por intermédio do referencial de testes de conhecimento papel-lápis, na maioria das vezes individuais e anotadas"(8).

Para se esvaziar o sentido atual, ou seja, a mensuração de resultados, o grau de alcance em relação a determinados objetivos e a ênfase na subjetividade, deve-se considerar novas formas de avaliação.

\section{AVALIAÇÃO FORMATIVA: UM RECURSO PARA O ENSINO} POR COMPETÊNCIAS

Na mais variada literatura sobre 0 assunto ${ }^{(3,8,21-23)}$, a Avaliação Formativa desponta como um recurso também de aprendizado por "envolver os alunos na avaliação de suas competências, explicitando e debatendo os objetivos e os critérios, favorecendo a avaliação mútua, os balanços de conhecimentos e a auto-avaliação $0^{(18)}$.

A Avaliação Formativa compreende a operacionalização de etapas que visam, primordialmente, a adequação das atividades desenvolvidas na prática com a construção das competências desejadas pelos alunos e professores.

Nesse modelo de avaliação, 0 objeto da avaliação deixa de se centrar exclusivamente nos resultados obtidos e se situa, prioritariamente, no processo ensino/aprendizagem. As etapas são(8,23):

- O primeiro passo do processo, a avaliação inicial, consiste em conhecer o que cada um dos alunos sabe, o que querem saber, quais os instrumentos que já dispõem, e quais as limitações já vivenciadas.

- Tendo por base os objetivos e conteúdos de aprendizagem previstos, o professor deve estabelecer as atividades e tarefas. $\mathrm{Na}$ medida que o professor vai conhecendo a maneira como cada aluno aprende e comparando às necessidades de aprendizagem, alterações podem ser realizadas, neste momento o professor realiza uma avaliação reguladora.

- O termo "formativo" designa a "modificação e a melhora contínua do aluno que se avalia" uma vez que a valoração do processo de aprendizagem tanto pelo docente como pelo aluno oportuniza, ao aluno, propostas educacionais mais adequadas.

- Na avaliação final, os resultados são apurados. Analisa-se 0 desempenho do aluno, se ele atingiu os resultados obtidos, ou seja, as competências adquiridas ou aperfeiçoadas em relação aos objetivos previstos e também se analisa o processo e o progresso de cada aluno.

- Considerando a aprendizagem como um processo contínuo, professor e aluno devem discutir sobre o que foi desenvolvido e realizar previsões sobre o que é necessário continuar fazendo ou o que é necessário fazer de novo. Esta etapa, chamada avaliação integradora, é especialmente importante para que 0 aluno possa continuar sua formação, considerando suas características específicas.

Em se tratando da construção de competências, os conteúdos factuais/conceituais, procedimentais e atitudinais estão integrados nesse processo e os elementos constituintes de cada dimensão foram descritos e interpretados por nós no Quadro 1, com a intenção de concretizar 0 modelo de avaliação apresentado. 
Capacidade de apreender conceitos
-Verificar se os alunos compreendem o significado dos conceitos e se conseguem verbaliza-los com as próprias palavras.

Qualidade dos conhecimentos prévios

- Analisar os conceitos que já foram aprendidos pelo aluno, a quantidade e a qualidade.

Atenção/ motivação: consciência do processo de construção

-Analisar o envolvimento do aluno no processo ensino-aprendizagem e se ele compreende o sentido das atividades.

Interpretação lógica: capacidade de resumir idéias importantes

- Avaliar se 0 aluno interpreta corretamente uma atividade proposta.

-Averiguar a capacidade do aluno de interpretar os conteúdos que foram ou estão sendo discutidos.

Capacidade de abstração

-Avaliar a qualidade do entendimento do aluno mediante a exposição de uma situação, ou seja, do aluno construir sistemas e teorias abstratas sobre os conceitos abstratos.

Capacidade para comparar e diferenciar

-O aluno deve ter condições intelectuais de comparar diferentes situações, destacar os pontos comuns e os pontos discordantes.

CONTEÚDOS PROCEDIMENTAIS

Capacidade de ordenamento de uma ação

- Avaliar o aluno na construção de uma ação com seqüência lógica. Ex. Planejar a execução de uma técnica/ um procedimento; Orientar e/ou Educar o paciente sobre sua doença ou tratamento; Planejar uma intervenção coletiva.

\section{Capacidade de execução da ação}

$\bullet$ aluno, após o planejamento de uma ação, deve conseguir cumpri-la. Neste item pode-se avaliar no aluno: Habilidades Manuais/ Psicomotoras; a Criatividade; a Prontidão; a Praticidade.

Aplicação de uma ação em contextos diferenciados.

• $O$ aluno deve ser capaz de, progressivamente, "aproveitar" métodos/ técnicas/ soluções de uma ação em outra, principalmente ante uma "nova" ação. Nesse momento o aluno estará ampliando suas competências específicas e conseguindo maior autonomia nas ações da profissão.

Capacidade de resolução eficaz

- Uma ação competente associa eficiência (capacidade de obter maior rendimento com o mínimo de desperdício) e efetividade (bons resultados na vida real). Sendo assim, 0 professor deve avaliar as ações do aluno e incentivá-lo a "qualificar" as suas ações, resgatando, inclusive, os Direitos dos Pacientes

\section{CONTEÚDOS ATITUDINAIS}

Amadurecimento Afetivo/ Compromisso de conhecer algo

-O aluno deve apresentar "desejo" de aprender. Na medida que a situação a que está exposto traz dúvidas/ apreensões/ sofrimento psíquico, o processo de aprendizado não se

realiza. É necessário que professor e aluno avaliam as emoções que permeiam diferentes situações na prática e que busquem recuperar a motivação para 0 aprendizado.

- $O$ aluno deve ser avaliado na capacidade de identificação desses fatores e no esforço de superação.

- O aluno deve comprometer-se com os acordos firmados com o professor em relação aos horários, cumprimento de atividades e adequação às condições impostas pela unidade de estágio.

Qualidade do pensamento crítico

- Avaliar a capacidade do aluno de conflitar dados, analisar os valores decorrentes de diferentes situações; colocar-se em diferentes posições; exercer a empatia

- Avaliar a capacidade do aluno de relacionar determinadas normas com os valores próprios, com os direitos alheios, com os contextos históricos e institucionais.

Capacidade de tomar decisões

-A tomada de decisão engloba uma tomada de posição, na qual o aluno deve defender seus pontos de análise e responsabilizar-se pelos seus atos.

Possibilidade de analisar situações considerando os pontos positivos e negativos

-Possuir uma postura aberta, reflexiva, ponderada sobre as diferentes possibilidades de resolução de um problema/ situação.

Possuir envolvimento afetivo e ético

- O aluno deve ser capaz de contextualizar situações, adotar posturas condizentes com os próprios referenciais de conduta e considerar os códigos de Ética pertinentes à situação.

Capacidade de revisar situações e avaliar-se

- $O$ aluno deve ser capaz de rever suas avaliações e suas decisões com senso crítico e construtor.

$\bullet O$ processo de auto-avaliação não é fácil, exige maturidade, objetividade e capacidade de mudança do aluno.

\section{Quadro 1. Descrições e interpretações dos conteúdos Factuais/Conceituais, Procedimentais e Atitudinais. São Paulo, 2002.}

A compreensão sobre os significados dos conteúdos imbricados no processo ensino-aprendizagem como também das bases analíticas que conformam as formações nos diferentes níveis de titulação superior, são importantes, porém não suficientes para que, como num passe de mágica possam surtir efeito na prática. Certamente deve haver um tempo de discussão, como também genuíno interesse por parte do grupo de docentes para que novas propostas ganhem vida.

O ritmo cadenciado da condução do processo educativo no ensino superior é citado por Moreira ${ }^{(24)}$. Em seus estudos, 0 autor pôde perceber que, em termos de técnicas de ensino, "há uma certa limitação de muitos docentes nesta área". O autor pontuou duas possibilidades analíticas para o fato: "uma referente aos entraves impostos pelas próprias instituições que, muitas vezes, não oferecem o mínimo de condições para que o professor possa pensar em opções diferentes"; outra relaciona -se ao fato que, ao contrário dos alunos que conferem especial importância para as técnicas de ensino, "informações provenientes de trabalhos voltados às questões didáticas do ensino universitário mostram um certo descaso dos docentes em relação a esta problemática".

Os alunos exageradamente adeptos do ensino estruturado, ou seja, baseado em aulas expositivas, disponibilidade de resumos e apostilas, pouca exigência de leitura complementar, geralmente apresentam baixo nível conceitual. O nível conceitual de uma pessoa, segundo Moreira ${ }^{(24)}$, 
"descreve o seu desenvolvimento em termos de aumento de complexidade nas formas de processar as informações, aumento da responsabilidade e de interdependência". Ao contrário, os alunos com alto nível conceitual são capazes de "gerar novos conceitos, sustentar padrões internos e assumir diferentes perspectivas".

Em termos relacionais, o comportamento afetivo do docente também tem demonstrado influenciar o processo ensino-aprendizagem, havendo preferência por docentes que mantenham o clima de diálogo, o entusiasmo sobre a própria profissão e atitudes de encorajamento, atenção e de bom humor ${ }^{(24,25)}$.

Procurar vencer todos esses obstáculos significa investir na construção de competências inerentes a carreira docente para que a construção de um profissional competente não permaneça como um desejo, uma necessidade percebida e verbalizada, porém sem expressões de efetividade ${ }^{(26)}$.

\section{REFERÊNCIAS}

1. Machado NJ. Ensaios transversais: cidadania e educação. São Paulo (SP): Escrituras Editora; 1997.

2. Stein E. Aspectos filosóficos e sócio-antropológicos do construtivismo pós-piagetiano II. In: Grossi EP, Bordin J. Costrutivismo póspiagetiano: um novo paradigma sobre a aprendizagem. Petrópolis (RJ): Vozes; 1993. p.35-42.

3. Morin $\mathrm{E}$. Os sete saberes necessários à educação do futuro. São Paulo (SP): Cortez; 2001.

4. Perrenoud P. Dez novas competências para ensinar. Porto Alegre (RS): Artes Médicas Sul; 2000.

5. Coll C, Juan IP, Sarabia B, Valls E. Os conteúdos na reforma: ensino e aprendizagem de conceitos, procedimentos e atitudes. Porto Alegre (RS): Artes Médicas; 2000.

6. Os novos pensadores da educação. Nova Escola 2002; 8: 18-25.

8. Machado NJ. A universidade e a organização do conhecimento: a rede, 0 tácito, a dádiva. Estudos avançados 2001; 15(42): 333-52.

9. Perrenoud P. Costruir as competências desde a escola. Porto Alegre (RS): Artes Médicas; 1999.

10. Ide CAC, De Domenico EBL. A proposta construtivista no ensino da enfermagem. In: Ide CAC, De Domenico EBL. Ensinando e aprendendo um novo estilo de cuidar. São Paulo (SP): Atheneu; 2001. p.109-18.

11. Ide CAC, Schneck CA. O contrato simbólico no processo ensinoaprendizagem: uma abordagem interativa. In: Ide CAC, De Domenico EBL Ensinando e aprendendo um novo estilo de cuidar. São Paulo (SP): Atheneu; 2001. p.137-51.

12. Backes VMS. Estilos de pensamentos e práxis na enfermagem: a contribuição do estágio pré-profissional. ljuí (RS): Ed. UNIJUÍ; 2000.

13. Lunardi Filho WD. Prazer e sofrimento no trabalho: contribuições à organização do processo de trabalho da enfermagem. Rev Bras Enferm 1997; 50(1):77-92.

14. Ide CAC, Chaves EC. Educação em enfermagem: o movimento constituinte da sua identidade. Rev Esc Enferm USP 1996; 30(3): 371-9.

\section{CONSIDERAÇÕES FINAIS}

As referências para o ensino por competências aqui apresentadas trazem questões complexas, merecedoras de reflexão e ampla discussão nos contextos de prática. Assumir que o ensino por competências é apenas a ponta mais visível de uma mudança radical de conceitos, significa dizer que romper com os antigos paradigmas é condição existencial para esta abordagem.

$\mathrm{Na}$ Enfermagem, as rupturas paradigmáticas geralmente vêm atreladas a processos caracteristicamente lentos e sobremaneira mais dependentes de fatores externos do que das próprias avaliações no âmbito interno da profissão. Contrariando essa trajetória, seria importante investir em novas propostas de formação e atuação profissional, tendo essa, ou qualquer outra baliza de referência para sustentar as mudanças e, assim, desvincular a profissão da postura reativa.

15. Demo P. Educar pela pesquisa. $4^{\mathrm{a}}$ ed. Campinas (SP): Autores Associados; 2000.

16. Grossi EP, Bordin J, organizadores. Construtivismo pós-piagetiano. $6^{\mathrm{a}}$ ed. Petrópolis (RJ): Vozes; 1993.

17. Castorina JA, Ferreira E, Lerner D, Oliveira MK. Piaget Vygotsky: novas contribuições para o debate. São Paulo (SP): Ática; 1995.

18. Cocco MIM, Bagnato MHS. Educadores e educandos em enfermagem: possíveis alternativas em um mundo em mudança. Texto Contexto Enferm 1999; 8: 53-60.

19. Waldow VR. Desenvolvimento do pensamento crítico na enfermagem. In: Waldow VR, Lopes MJM, Meyer DE. Maneiras de cuidar: maneiras de ensinar: a enfermagem entre a escola e a prática profissional. Porto Alegre (RS): Artes Médicas; 1995. p.109- 29.

20. Pereira RCJ. Refletindo e escrevendo sobre as experiências vivenciadas no contexto da escola e do cuidado. In: Waldow VR, Lopes MJM, Meyer DE. Maneiras de cuidar: maneiras de ensinar: a enfermagem entre a escola e a prática profissional. Porto Alegre (RS): Artes Médicas; 1995. p.135-49.

21. Cianciarullo TI. Especialização: A contextualização do futuro da enfermagem. In: Santos VLCG; Cessaretti IUR. Assistência em estomaterapia: cuidando do ostomizado. São Paulo (SP): Atheneu; 2000.

22. Vygotsky LS. A formação social da mente. $4^{\mathrm{a}}$ ed. São Paulo (SP): Martins Fontes; 1991.

23. Oliveira MK. Pensar a educação: contribuições de Vygotsky. In: Castorina JA, Ferreira E, Lerner D, Oliveira MK. Piaget Vygotsky: novas contribuições para o debate. São Paulo (SP): Ática; 1995. p.53-81.

24. Zabala A. A prática educativa: como ensinar. Porto Alegre (RS): Artmed; 1998.

25. Moreira DA. Didática do ensino superior: técnicas e tendências. São Paulo (SP): Pioneira; 1997.

26. Pimenta SG, Anastasiou LGC. Docência no ensino superior. São Paulo (SP): Cortez; 2002. 